\title{
Monitoring Kids: How Much Is Enough?
}

\author{
Brenda K. Wiederhold, PhD, MBA, BCB, BCN
}

W HEN WE IMAGINE young students starting their days in the classroom, most of us picture them cracking open a book. But increasingly, many students around the world instead begin by prepping electrodes and fastening their brain monitoring devices.

A recent story in the Wall Street Journal ${ }^{1}$ highlights the use of this type of advanced technology in classrooms in Jinhua Xiaoshun Primary School in eastern China. The devices look like headbands with three electrodes (one on the forehead and one behind each ear) used to monitor the electrical activity in each student's brain. Students are then assigned a meditative exercise and a competition task, both of which are meant to prepare their minds for learning. The data from devices are sent to the teacher's computer where he or she can keep an eye on each student's progress. The headbands remain on the students during their traditional learning activities as well, continuing to measure their levels of focus throughout the day. ${ }^{1}$

If you think about it, technology has always been an important part of education. ${ }^{2}$ From photocopying to mass production of books, from chalkboards to slide projectors to smartboards, technology has enabled more efficient and effective education. And while the headband devices described above may seem like science fiction to us now, these types of advanced technologies have been slowly oozing into the "traditional" classroom setting for decades. In the United States, students have gone from having limited and periodic access to computers for learning keyboard skills and playing primitive games, to many having an individually assigned Chromebook on which they complete scientific research, collaborate with their peers and teachers, and play artificial intelligence (AI) embedded games to improve their math and literacy skills.

And while there has been some pushback to the expansion of these types of technologies to the classroom (e.g., too much screen time for children and funding and maintenance concerns), for the most part, people are on board with at least some inclusion of basic computers in the school environment.

But what about other more cutting-edge advanced technologies? Why not multi-touch workstations that allow students to collaborate with each other, both within the classroom and around the world? Why not augmented reality (AR) glasses that can layer facts and information atop students' interactions with their natural environments? For that matter, why not biometrics to evaluate the physical and emotional states of students in the classroom, allowing teachers to alter course material based on each student's immediate state of being ? $^{2}$ Did that last one go too far? And if so, where exactly is the line between technology use that is acceptable and that which is intrusive?
New technologies such as AI, machine learning, and educational software are providing ways for learning to become increasingly personalized and therefore more effective. AI has made individualized tutoring accessible on a large scale. These technologies are not only changing the field for students, they're reshaping the role of educators and remaking the entire classroom concept into one that is broader, more interactive, and more based on individual learning styles and needs. ${ }^{3}$

Yet, some critics view the type of "smart education" described above as invasive. Even while admitting that it is perhaps a cost-effective method of personalizing and therefore improving education, they site overwhelming concerns of "big brother" type governmental oversight. ${ }^{1}$

A recent article in the Washington Post ${ }^{4}$ examines the encroachment of monitoring technologies on college campuses. Dozens of schools have begun to use campus wireless networks and short-range phone sensors to track the locations and activities of their student bodies precisely. In fact, one company using such technology boasts that it gathers up to 6,000 location data points per student each day. ${ }^{4}$ Proponents of this type of technology assert that monitoring students' activities in this way allows administrators to track students' academic performance, analyze their conduct, and assess their mental health status. It enables schools to watch out for their students, increasing their chances of success. Yet, opponents argue that these tracking technologies are intrusive and invade students' privacy. Not only that, but these types of oversight infantilize students at the exact time and place where they are attempting to develop their skills as adults. ${ }^{4}$ (Consider the 2017 Black Mirror episode titled "Arkangel" whereby implanted chips allowed parents to track and monitor their children.) 5

There are also concerns about what happens to the data collected from children. It is well known that apps amass our personal information and sell those data to advertisers. ${ }^{6}$ As adults, we are supposedly capable of making our own decisions about what data to give to apps and when. But children are not yet as tech savvy as adults and also may feel they have no choice about what and how much information to give. There may be an element of pressure from peers, or even teachers, to complete certain activities that they or their parents may not be comfortable with.

To combat this, experts say that we need to teach children to collaborate with machines rather than be threatened by them. ${ }^{7}$ Children are growing up in a world where technology cannot be avoided. It is an essential part of our days that is 
only becoming more integral to all spheres of life, from our homes to the workplace. And children cannot opt out any more than adults can.

So, how can we make our children safer? One way to combat the concerns about data monitoring in the classroom is to educate our children about technology and give them the skills necessary to interact with it safely. This education can begin as early as preschool and then continue throughout their formative years. ${ }^{7}$ The American Academy of Pediatrics even recommends creating a family media use plan in which both parents and children collaborate on ways to use media thoughtfully and appropriately to enhance their daily lives. ${ }^{8}$

Another way to prevent media misuse is to monitor children's technology consumption. This can range from limiting screen time both in quantity and times of the day to utilizing one of the many apps that allow parents to observe their children's activities. ${ }^{9}$ However, these apps raise a number of interesting questions in and of themselves. Is it ethical to monitor our children's activities so closely? Will children balk at this close level of supervision? And if parents rely on these apps to police their children, how do the children learn how to manage their technology consumption as adults?

Just as with any new influence, parents must grapple with how much technology access to allow their children. Overseeing children's technology use is a key responsibility of modern parenting. But studies do show that tightening the reigns too much and exerting too much control over technological interactions can backfire, leading to resentment among children. ${ }^{10}$ So, experts suggest beginning with more strict controls when children first get access to the Internet, and then loosening these restrictions gradually as the child grows and gains technological literacy. ${ }^{9}$ Using these parental controls is a process, and these products are not a solution on their own but rather tools to be wielded appropriately. The functions of these products (blocking inappropriate content, managing screen time, etc.) are ultimately the things that parents would like their children to be able to do themselves. So, at some point, parents eventually need to hand over control, both inside the classroom and beyond.

It can be a tightrope walk to find the right balance when it comes to technology, not only for children but for adults as well. The key is to stay aware and to decide continually, for ourselves and for our children, at each individual moment and interaction, when the benefits of technology outweigh the drawbacks.

\section{References}

1. Wang Y, Hong S, Tai C. China's efforts to lead the way in AI start in its classrooms. Wall Street Journal, Oct. 25,
2019. https://www.wsj.com/articles/chinas-efforts-to-leadthe-way-in-ai-start-in-its-classrooms-11571958181 (accessed Jan. 5, 2020).

2. Purdue Online. The evolution of technology in the classroom. https://online.purdue.edu/blog/evolution-technologyclassroom (accessed Jan. 5, 2020).

3. Bernard Z. Here's how technology is shaping the future of education. Business Insider, Dec. 27, 2017. https://www .businessinsider.com/how-technology-is-shaping-the-futureof-education-2017-12\#and-despite-the-inundation-of-techno logy-within-the-classroom-its-role-still-remains-to-be-deter mined-7 (accessed Jan. 5, 2020.

4. Harwell D. Colleges are turning students' phones into surveillance machines, tracking the locations of hundreds of thousands. Washington Post, Dec. 24, 2019. https:// www.washingtonpost.com/technology/2019/12/24/collegesare-turning-students-phones-into-surveillance-machinestracking-locations-hundreds-thousands/ (accessed Jan. 5, 2020).

5. “Arkangel.”' Black Mirror, Season 4, Episode 2, Dec. 29, 2017. Netflix, https://www.imdb.com/title/tt5709250/

6. Thurm S, Kane YI. Your apps are watching you. Wall Street Journal, Dec. 18, 2010. www.wsj.com/articles/SB1000 1424052748704368004576027751867039730 (accessed Jan. 5, 2020).

7. Shellenbarger S. Why we should teach kids to call the robot "It." Wall Street Journal, Aug. 27, 2019. https://www.wsj .com/articles/why-kids-should-call-the-robot-it-11566811801 (accessed Jan. 5, 2020).

8. American Academy of Pediatrics. Family media plan. https://www.healthychildren.org/English/media/Pages/default .aspx ?fbclid=IwAR3M4H9m0xHdYF4PF9SKYUj-PVA0_ MLIV-dJK6L_1Hu9b65PTnANPsRBWsU\#home (accessed Jan. 5, 2020).

9. Jargon J. Keeping tabs on your kids: the latest parental controls from Apple, Google and Amazon. Wall Street Journal, Sept. 17, 2019. https://www.wsj.com/articles/ keeping-tabs-on-your-kids-the-latest-parental-controls-fromapple-google-and-amazon-11568721601 (accessed Jan. 5, 2020).

10. Ghosh AK, Badillo-Urquiola KA, Guha S, et al. Safety vs. surveillance: what children have to say about mobile apps for parental control. In: CHI '18: Proceedings of the 2018 CHI Conference on Human Factors in Computing Systems. Paper No.: 124. New York: ACM Press, pp. $1-14$.
Brenda K. Wiederhold Editor-in-Chief 